\title{
Progresistas y revolucionarios: el Frente de Acción Popular y la Vía Chilena al Socialismo, 1956-1967
}

\section{Progressives and revolutionaries: the Popular Action Front and the Chilean Road to Socialism, 1956-1967}

\author{
Camilo Fernández Carrozza* \\ Pablo Garrido González
}

\begin{abstract}
Resumen: El presente trabajo examina el desarrollo del Frente de Acción Popular (FRAP), enfatizando el concepto de democracia y su relación con el concepto de revolución en el proyecto político de la izquierda chilena. Si bien reconocemos la importancia que tuvo el concepto de revolución para los dos principales partidos de izquierda del periodo, el Partido Comunista y el Partido Socialista, buscamos mostrar cómo el discurso del FRAP, en sus inicios, se funda sobre un discurso principalmente democrático y progresista, mas no abiertamente revolucionario, teniendo este último una aparición posterior en el proyecto de la coalición izquierdista.
\end{abstract}

Palabras clave: Frente de Acción Popular, Partido Comunista, Partido Socialista, Vía Chilena al Socialismo

\begin{abstract}
The present work examines the development of the Popular Action Front (FRAP), emphasizing the concept of democracy and its relation with the concept of revolution in the political project of the Chilean Left. Although we acknowledge the importance that the concept of revolution had for the two most important leftwing parties at the time, the Communist Party and the Socialist Party, we aim to show how the FRAP's discourse, in its origins, is based mainly on a democratic and progressive discourse, although not openly revolutionary, having the latter a later appearance in the leftist coalition's project.
\end{abstract}

Keywords: Popular Action Front, Communist Party, Socialist Party, Chilean Road to Socialism

Recibido: 12 julio 2016

Aceptado: 4 octubre 2016

\footnotetext{
* Chileno, MA in History, University of Nottingham. Investigador asociado al Programa de Historia de las Ideas Políticas en Chile, Universidad Diego Portales.

* Chileno, Mágister en Historia (C), Universidad de Santiago de Chile. Investigador asociado al Programa de Historia de las Ideas Políticas en Chile, Universidad Diego Portales.
} 


\section{Introducción}

Los trabajos desarrollados en torno al proyecto de izquierda del Frente de Acción Popular (FRAP) durante los años 60 e inicios de los 70 por la Unidad Popular (UP), tienden a enfatizar la importancia que adquirió el concepto de revolución. Desde aquel punto de vista, las principales propuestas, ideas y debates dentro de la izquierda se habrían expresado e interpretado mediante las discusiones en torno a la idea de la revolución, transformándose este en el concepto clave para la ideología socialista en Chile. Si bien concordamos en que dicho concepto ocupó un lugar fundamental en los dos principales partidos de la izquierda, el Partido Socialista (PS) y el Partido Comunista (PC), creemos que la importancia de este dentro del proyecto conjunto de la izquierda chilena merece ser matizado.

En general, en la bibliografía sobre el proyecto de la izquierda y la cuestión de la revolución durante los años 60 e inicios de los 70 se pueden encontrar diversas interpretaciones. Por ejemplo, Pinto ha sostenido que entre los partidos revolucionarios chilenos había "bastante concordancia respecto de los fines últimos que se perseguían, y al tipo de sociedad que se aspiraba a construir. Esta debía ser socialista, anti-imperialista (...) humanista e igualitaria". 1 Sin embargo, para el autor, el proyecto de la izquierda daba mayor importancia a los medios, en los que las vías al socialismo eran un punto central del debate. De manera similar, Casals mantiene que las formulaciones comunistas y socialistas acerca de la revolución "presentaban rasgos similares, con importantes confluencias tanto en los alcances y límites del proceso impulsado como en las tareas inmediatas a cumplir. Las diferencias son más que nada conceptuales y de consistencia".

Por otra parte, Joaquín Fermandois si bien reconoce que las diferencias entre ambos partidos tenían momentos de tensión y significaron focos de enfrentamiento dentro de la izquierda, pone de relieve la existencia de una meta común superior: la construcción del socialismo. En este sentido, el programa del FRAP no representaría cabalmente las intenciones de ambos partidos, pues "aparte de tener una tonalidad antiimperialista, que podría identificar a un vasto espectro del nacionalismo de izquierda en América Latina, ponía el acento en cambios económicos que sin duda provocarían una alteración mayor de la sociedad y de la economía chilena. No alcanzaban sin embargo, a delinear claramente una intención marxista, aunque comunistas y socialistas sí la tenían". ${ }^{3}$ En la misma línea, Julio Faúndez reconoce las diferencias existentes en la política de los partidos Socialista y Comunista, las cuales pasarían a un segundo plano considerando la oportunidad que representa el FRAP para alcanzar posiciones de poder y un eventual

\footnotetext{
${ }^{1}$ Julio Pinto, "Hacer la revolución en Chile", en J. Pinto (ed.), Cuando hicimos historia. La experiencia de la Unidad Popular, Santiago, Lom, 2005, p. 13.

${ }^{2}$ Marcelo Casals, El alba de una revolución. La izquierda y la construcción estratégica de la "vía chilena al socialismo". 1956-1970, Santiago, Lom, 2010, p. 51.

${ }^{3}$ Joaquín Fermandois, La revolución inconclusa. La izquierda chilena y el gobierno de la Unidad Popular, Santiago, Centro de Estudios Públicos, 2013, p. 106.
} 
triunfo en las elecciones presidenciales, posibilidad que se muestra cierta después de la elección de 1958. De esta forma, "el FRAP no fue concebido como un instrumento para resolver las diferencias ideológicas entre comunistas y socialistas, sino simplemente como una alianza que representaba la decisión de cada uno de mantenerse dentro de sus propias estrategias". 4

Una interpretación algo distinta es la Luis Corvalán Márquez, quien reconoce la existencia de desacuerdos significativos en la izquierda. De acuerdo al autor, entre socialistas y comunistas había "dos concepciones del todo distintas respecto del proceso revolucionario a impulsar. Las diferencias (...) permiten suponer que, más allá de la lucha por el poder, el tipo de socialismo a implementar que hubiera propuesto cada partido seguramente también hubiera sido distinto". 5 No obstante esta afirmación, Corvalán se concentra principalmente en la cuestión sobre las vías al socialismo y la revolución, y no ofrece un análisis más profundo sobre las diferencias que indica. A pesar de ello, nos parece que lo comentado por Corvalán apunta en la dirección correcta, pues un paso necesario para analizar las particularidades del socialismo en Chile en el periodo acá estudiado es ir más allá de las meras discusiones respecto a las vías al socialismo y la cuestión del poder.

En este sentido, nuestro propósito es mostrar que los debates y proyectos elaborados por la izquierda en torno al FRAP tuvieron implicancias conceptuales más profundas de lo que suele reconocerse. Por esto creemos que uno de los conceptos centrales para analizar el proyecto socialista que culmina con la formación de la UP es el de democracia. En este punto, concordamos con la interpretación de Alan Knight al sostener que en Latinoamérica los proyectos revolucionarios se planteaban como formas alternativas de democracia, reclamando superioridad sobre la "democracia burguesa" en términos de "dos supuestas ventajas: primero, mayor representación (una representación más directa, transparente e inherentemente democrática), y segundo, una mayor provisión de bienestar y beneficios socio-económicos". ${ }^{6}$ En lo que sigue, trataremos de mostrar cómo los postulados democráticos, de acuerdo a estas dimensiones apuntadas por Knight, constituyen parte central del FRAP en sus inicios, sirviendo como base para su desarrollo en la segunda mitad de los '60 aun cuando el concepto de revolución los sobrepasará en importancia discursiva.

Para desarrollar lo anterior, recurrimos como enfoque a la historia intelectual entendida en términos amplios, esto es, como lo ha sintetizado Skinner, el estudio de los "pensamientos pasados", o como lo explica Pocock refiriéndose a su propia aproximación, el estudio de la historia de los discursos políticos, esto es, el "discurso (speech), la literatura y las declaraciones públicas en general, que involucran un

\footnotetext{
${ }^{4}$ Julio Faúndez, Izquierdas y democracia en Chile 1932-1973, Santiago, Ediciones BAT, 1992, p. 166.

${ }^{5}$ Luis Corvalán Marquez, Del Anticapitalismo Al Neoliberalismo en Chile: Izquierda, Centro y Derecha en la Lucha Entre Los Proyectos Globales. 1950-2000, Santiago, Editorial Sudamericana, 2002, pp. 56-57.

${ }^{6}$ Alan Knight, "Democratic and Revolutionary Traditions in Latin America", Bulletin of Latin American Research, Vol. 20, №2, abril 2001, p. 148.
} 
elemento de teoría y se llevan a cabo en una variedad de contextos". ${ }^{7}$ Considerando el campo político como un área de la historia intelectual, nos interesa conocer cómo los actores estudiados articulaban y producían las ideas y conceptos que daban forma a un corpus de pensamiento particular que sostenía su acción política. Para ello, nos resulta particularmente útil el enfoque desarrollado por Michael Freeden, quien se ha aproximado a la materia desde el punto de vista de las ideologías como una forma particular de pensamiento político. Para Freeden, las ideologías políticas se definen como configuraciones distintivas de conceptos políticos, cuyas variaciones dependen de las distintas relaciones y agrupaciones conceptuales. ${ }^{8}$ De esa forma, toda ideología necesitará para definirse un conjunto de conceptos nucleares ineliminables (que la diferencia de otras ideologías), así como diversos conceptos e ideas adyacentes que definen sus distintas variantes. Esto, en concordancia con lo apuntado por Skinner o Pocock, posee una fuerte carga histórica. Por un lado, dado que los conceptos políticos son constructos que reflejan un uso social e histórico de las palabras, la comprensión de toda configuración ideológica requiere necesariamente estudiar el desarrollo histórico de los lenguajes, palabras y discursos que le dan forma. ${ }^{9}$ Por otro, la ordenación conceptual particular que delinea a todas las ideologías sólo puede alcanzarse a través del tiempo y variará dependiendo de cada contexto histórico.

Dicho esto, nos parece que un análisis más detenido sobre la presencia del concepto de revolución revela que si bien ésta mantiene un lugar decisivo en el entramado conceptual del socialismo chileno, su presencia no se manifiesta con la misma intensidad en el proceso político que culmina con la formación de la Unidad Popular. Por el contrario, si nos centramos en la coalición previa a la UP, el Frente de Acción Popular, se puede evidenciar que el concepto de revolución no aparece sino progresivamente a medida que avanza la década del 60. A pesar de la fuerte irrupción del concepto a partir de la coyuntura electoral de 1964, su desarrollo no puede explicarse sin la trayectoria previa de otro concepto importante: democracia. Así, sostenemos que gran parte de los postulados presentes en el proyecto político conjunto de comunistas y socialistas son inicialmente interpretados y expresados a través del concepto de democracia, y no revolución. Esto debido a que la palabra democracia se encuentra estrechamente ligada a nociones de autodeterminación y autogobierno, cruciales en el discurso de la izquierda, a los cuales se les adhieren ideas en torno a igualdad económica y justicia social; estos elementos que luego aparecerán incluidos o relacionados al concepto de revolución, parecen prescindir de este último para ser expresados, teniendo la palabra revolución una presencia considerablemente menor en la primera campaña del FRAP en comparación al periodo cercano a la elección de 1964 y posterior a la derrota a la hora de conceptualizar el proyecto político de la izquierda chilena.

\footnotetext{
${ }^{7}$ Stefan Collini et al, "What is intellectual history?", History Today, Vol. 35, No 10 , octubre 1985, pp. 50, 52.

${ }^{8}$ Michael Freeden, Ideologies and Political Theory. A Conceptual Approach, Oxford, Oxford University Press, 1996, p. 48.

${ }^{9}$ Ibíd., p. 52.
} 
No obstante, es necesario aclarar que nuestra interpretación no implica subestimar el peso del concepto de revolución. Al contrario, las fuentes correspondientes a cada uno de los partidos nos revelan que dicho concepto, a pesar de su presencia irregular en algunos periodos, es un tópico central tanto en el PC como en el PS. Más bien nuestro argumento sostiene que el concepto de revolución ocupó un lugar definitorio en la ideología socialista, es decir, que su presencia -a diferencia de otras ideologías que podían prescindir de dicho concepto sin perder sus rasgos definitorios, como en el caso de la Democracia Cristiana (DC)- era un elemento necesario para configurar la misma. Sin embargo, paralelamente a la relevancia de dicho concepto, queremos poner énfasis en las nociones de democracia elaboradas por los mismos partidos, y que abarcan, en términos conceptuales, un espectro amplio de definiciones que no pueden ser explicadas totalmente por la idea de revolución. En ese sentido, nuestro análisis busca dar la justa importancia a cada uno de estos términos de acuerdo a los discursos elaborados tanto en conjunto como individualmente por el PC y el PS.

Para lograr nuestros objetivos, hemos seleccionado una diversidad de fuentes primarias. Por un lado, utilizamos, fuentes del FRAP (programas y declaraciones oficiales), con el fin de identificar cómo dicha coalición política funciona como punto de encuentro entre comunistas y socialistas, y analizando hasta qué punto presenta un discurso diferente de ambos partidos. Por otro lado, y a modo de contrastar lo anterior, revisamos también fuentes del PC y PS, principalmente declaraciones de sus dirigentes así como sus revistas teóricas, Principios y Arauco respectivamente. Siguiendo esta estrategia de contrastar las fuentes de la coalición con la de los partidos que la conformaron, nuestro artículo se divide en cuatro secciones. En un primer momento examinamos la etapa fundacional del FRAP desde 1956 hasta su primera elección en 1958, periodo que se caracteriza por un fuerte intento de delinear el contenido de la coalición, presentando un elaborado programa presidencial de carácter más bien progresista y democrático. Luego, en las dos secciones siguientes analizamos las coyunturas y procesos políticos que comienzan a influir dentro de la izquierda y que, progresivamente comienzan a transformar el discurso común que se había levantado alrededor del FRAP. La irrupción de la revolución democratacristiana, el éxito de la Revolución Cubana y las elecciones de 1964 que tensionan las relaciones entre comunistas y socialistas marcan el auge de un lenguaje abiertamente revolucionario. Finalmente, se revisan las consecuencias de la derrota de la izquierda en 1964, que termina por consolidar del concepto de revolución y resulta en el debilitamiento del discurso inicial del FRAP. De esta forma, más que establecer definiciones generales previas, buscamos mostrar cómo los conceptos mencionados van apareciendo, cómo son definidos en distintos momentos clave para la izquierda chilena, y qué relaciones se establecen entre ellos.

\section{Un camino nuevo para Chile: la construcción de un proyecto socialista}

El FRAP nace formalmente el primero de marzo de 1956 tras la alianza del Frente Nacional del Pueblo, constituido por el Partido Socialista de Chile y el ilegalizado Partido Comunista además del Bloque Democrático Socialista compuesto por el Partido 
Socialista Popular y algunos partidos de menor cuantía. De esta forma el FRAP aparece como la primera instancia unitaria de la izquierda chilena luego de un periodo de escisiones internas, persecuciones y distanciamientos entre los partidos Comunista y Socialista Popular, definiéndose como "una organización política unitaria de las fuerzas de avanzada que concentrará la acción de los partidos que la constituyen en el campo político, parlamentario, sindical y electoral". 10

La plataforma de acción inmediata del FRAP está marcada por la urgencia de las elecciones para regidores del año 1956 pero también por el proceso de debate en el contexto de crisis inflacionaria de mediados de la década del 50 y la ilegalidad del PC. En este aspecto, y debido a las medidas anti inflacionarias propuestas por la misión Klein-Saks, buena parte de los esfuerzos iniciales de la unidad apuntan al problema del salario vital obrero y poner fin a la ley de Defensa Permanente de la Democracia. En este sentido, el FRAP aparece como un espacio de acción concertada, donde según el diagnóstico de los partidos participantes se hace "necesario fortalecer la unidad de los partidos populares, para hacer frente a una política represiva y antipopular, y para promover una nueva política de claro sentido nacional, democrático y progresista" 11

Los documentos iniciales del FRAP muestran que la coalición incluye una variedad de conceptos que si bien corresponden a elementos que permanecerán a lo largo de los sesenta hasta llegar a la UP, su presencia no se articula inmediatamente en torno al concepto de revolución como ocurrirá a fines de la década del 60. Más aún, cabe destacar que en los documentos fundacionales y el programa de campaña para 1958, la palabra revolución se encuentra totalmente ausente. Aparecen por cierto componentes que eventualmente servirán de base para un discurso revolucionario, pero que en un primer momento se expresan en el marco de un proyecto eminentemente democrático, progresista y transformador. Ejemplo de esta particular configuración conceptual se encuentra en el Acta Constitutiva del FRAP, en la cual además de reafirmar el carácter anti-imperialista, anti-oligárquico y anti-feudal (elementos ya típicos y compartidos por la izquierda en ese momento), declara que el FRAP busca consolidar un movimiento de masas que:

(sirva) de base social a un nuevo régimen político y económico, inspirado en el respeto a los derechos y aspiraciones de la clase trabajadora y dirigido a la emancipación del país, al desarrollo industrial, a la eliminación de las formas precapitalistas de la explotación agraria, al perfeccionamiento de las instituciones democráticas y a la planificación del sistema productivo con vistas al interés de la colectividad y a la satisfacción de la necesidades básicas de la población trabajadora ${ }^{12}$

\footnotetext{
${ }^{10}$ FRAP, "Pacto del Frente de Acción Popular", Boletín del Comité Ejecutivo del PSP, No4, febrero de 1956, p. 1.

${ }^{11}$ FRAP, "Conclusiones de la Conferencia Nacional del FRAP", Boletín del Comité Ejecutivo del PSP, $\mathrm{N}^{\circ} 14$, enero de 1957, p. 7.

${ }^{12}$ FRAP, "Pacto del Frente de Acción Popular", p. 1
} 
La definición resulta relevante en tanto reúne ideas básicas en la ideología socialista chilena. Está presente la idea de progreso histórico, social y económico al señalar la necesidad de un nuevo régimen, expresado en la emancipación nacional (o independencia en otros documentos) y el abandono de formas económicas y de producción consideradas como atrasadas. A su vez, éstas están expresadas concretamente en ideas más específicas como industrialización y planificación, una democratización principalmente institucional y una fuerte presencia de bienestar social. Documentos posteriores tienden a consolidar estos conceptos. En la Conferencia Nacional del FRAP de enero de 1957, se mantiene, por ejemplo, que el FRAP lucha "por la implantación de un Gobierno popular capaz de alcanzar la emancipación social y la liberación nacional", lo cual sumado a las reivindicaciones económicas del pueblo, la protección, nacionalización y planificación de los recursos y de la producción, busca afianzar la "independencia económica, la elevación del nivel de vida de las masas y el desarrollo de nuestras fuerzas productivas". ${ }^{13}$ Más relevante aún resulta en este documento la idea de democracia entendida en términos más amplios como participación popular, aunque todavía ligada a sus formas institucionales:

Democratizar nuestro régimen político con el fin de vincular a los más amplios sectores populares a la formación de los poderes públicos y al desarrollo de su gestión gubernativa, ampliando el cuerpo electoral, derogando las leyes represivas y creando nuevas formas de incorporación del pueblo a la acción pública. ${ }^{14}$

Estas características del concepto de democracia comienzan a delinearse más claramente en los documentos de campaña. En la Plataforma Programática a la candidatura de Allende, junto a las reivindicaciones económicas que apuntan a una mayor independencia nacional, se sostiene que "hay que dar al pueblo acceso al Poder. (...) El propio pueblo de Chile debe tomar en sus manos la dirección del país, de acuerdo con los principios democráticos". ${ }^{15}$ Así, la idea sobre democracia comienza a ser entendida en función de mayor igualdad en términos de acceso al poder, es decir, desconcentrándolo de las instancias existentes desde las cuales se ejercía, y dando una amplia inclusión a las masas mediante el ejercicio del mismo. De ahí que el concepto de democracia aparezca como un objetivo central, en el sentido de ser un elemento que permite un cambio sustancial al régimen. "Planteamos", continúa el texto programático, "que terminen la verdadera dictadura legal del Presidente de la República y sus omnímodas atribuciones y se la reemplace por una democracia avanzada y profunda". ${ }^{16}$

En este marco, los cambios institucionales y económicos propuestos comienzan a adquirir precisamente un carácter transformador, abriendo la posibilidad de que estos en el futuro cercano sean posibles de ser interpretados y expresados como una revolución.

\footnotetext{
${ }^{13}$ FRAP, "Conclusiones de la Conferencia Nacional del FRAP”, p. 5.

${ }^{14}$ Ibid.

${ }^{15}$ FRAP, "Plataforma Programática de la Candidatura Presidencial del Pueblo", p. 4.

${ }^{16}$ Ibíd.
} 
Este potencial revolucionario del discurso frapista está latente, dado que, como mencionamos anteriormente, se encuentra en los debates internos de comunistas y socialistas, pero por el contexto de ese momento aún se encuentra limitado, o no encuentra las posibilidades de ser explicitado como coalición.

El proyecto democrático del FRAP adquiere entonces significados particulares y distintos a los que manejaban otros actores políticos de la época, que no terminan en la mera reproducción de las formas y procedimientos electorales, sin que esto implique una renuncia a la vía electoralista y a la formación de mayorías parlamentarias. La misma Conferencia Nacional del FRAP "plantea la necesidad de obtener en las elecciones de marzo próximo, una mayor representación e influencia de los trabajadores en el parlamento, para alcanzar en esta forma, un triunfo político que represente en la práctica un paso en el camino hacia la conquista del Poder". ${ }^{17}$ La misma posición será afirmada en una declaración pública del FRAP después de conocidos los resultados de la elección de marzo de 1957:

El Frente de Acción Popular no es un movimiento electorero y mantendrá implacablemente su posición política de independencia al margen de todo oportunismo. Esto no nos impedirá realizar en el Parlamento labor común con aquellas fuerzas que como el Partido Radical y la Falange y un sector agrariolaborista, dicen estar de acuerdo con nosotros frente a diversos problemas de índole económica y social. Las acciones comunes que emprenda el FRAP, en este terreno, estarán exclusivamente destinadas a facilitar el urgente despacho de aquellas leyes que el país reclama, y tendrán tan solo un limitado alcance parlamentario. ${ }^{18}$

Bajo este aparataje conceptual el FRAP llega a las elecciones de 1958. El Programa de ese año refrenda y expande los diversos elementos programáticos e ideológicos que el conglomerado venía desarrollando. El documento se estructura en torno a cuatro pilares fundamentales: democracia, desarrollo económico, bienestar social, e independencia nacional. De éstos, los dos primeros tienen una importancia fundamental. Respecto al primero, el documento comienza afirmando que "el sistema político vigente en Chile constituye un obstáculo al desenvolvimiento económico y social del país. No obstante su apariencia democrática, se ha convertido en una verdadera dictadura legal". ${ }^{19}$ Destaca en el texto que, por un lado, democracia aparezca no solo referida a sus formas institucionales, sino que se la relaciona explícitamente a lo económico. Además, aparece con fuerza otra caracterización de democracia que llegará a ser común en el discurso de la coalición, a saber, que el régimen político existente es democrático sólo en apariencia,

\footnotetext{
${ }^{17}$ FRAP, "Conclusiones de la Conferencia Nacional del FRAP”, p. 5.

${ }^{18}$ FRAP, "El FRAP y las elecciones”, Boletín del Comité Ejecutivo del PSP, №15, febrero-marzo, 1957. P.3

19 FRAP, Un camino nuevo para Chile: el programa del Gobierno Popular, Santiago, Impresora Horizonte, s/f, p. 8. Considerando que la Convención Presidencial del Pueblo se llevó a cabo en septiembre de 1957, es probable que el programa se publicara en 1958, mismo año de la elección.
} 
y de lo que se trata el proyecto izquierdista es de llegar a una democracia auténtica, cuestión sobre la cual se levantará en parte el debate en torno a la revolución.

El Programa continúa describiendo una serie de problemas institucionales de la época referentes a lo limitado del padrón electoral tanto entre civiles como militares, ya que se excluía a analfabetos y a la tropa, además de los comunistas marginados desde 1948; al cohecho; a la excesiva burocratización; y a las fallas en la legislación electoral que sobrerrepresentaba ciertas zonas. En este ámbito político-electoral, democracia se definirá en términos de mayor representación y autodeterminación. Así, por ejemplo, más democracia significará que "los destinos del país los resuelva la voluntad limpia y representativa de la gran mayoría de la población adulta"; que las autoridades electas "sean efectivamente responsables" ante las mayorías; o que desde el régimen institucional y empresarial "recojan las aspiraciones de los sectores asalariados afectados por su labor". ${ }^{20}$ Ante esto, las reformas propuestas serán de orden electoral e institucional, ampliando el padrón electoral, asegurando representación efectiva y eliminando la legislación represiva para asegurar derechos político-sociales.

Sin embargo, como ya indicamos, el programa agrega que las "deficiencias en lo político se reproducen en injusticias igualmente irritantes en lo económico" "21, refiriéndose a las excesivas desigualdades materiales y en la distribución de la renta, así como a las que se expresan en los aspectos productivos y en el régimen de propiedad, los que se manifiestan en términos legales. De esa forma, "todo el aparato legal, jurídico y constitucional vigente tiende a preservar el control político y económico de las fuerzas reaccionarias y a afianzar y cautelar sus intereses y acrecentar sus privilegios y a mantener y aumentar las desigualdades e injusticias existentes". ${ }^{22}$ El llamado es, pues, a una reestructuración sustantiva no sólo de las instituciones formales de la democracia, sino de asegurar una real democratización mediante cambios estructurales de la economía que permitan una igualdad efectiva.

En el ámbito estrictamente económico el programa del FRAP no difiere de los diagnósticos que postulan que el problema del desarrollo chileno se encuentra en la falta de productividad, el monopolio industrial y de la tierra, y la dependencia excesiva del capital extranjero como causantes, entre otras cosas, del fenómeno inflacionario y una participación desigual de la renta nacional entre trabajadores, empleados y capitalistas. El documento describe como los principales problemas del desarrollo económico chileno una estructura monopólica de las industrias, una dependencia del sector externo en términos políticos (mediante el acceso a créditos condicionados) y a las fluctuaciones de los precios de las exportaciones de mineral determinados por el mercado internacional, además de un déficit en la formación de capital social básico (como lo son los caminos, el desarrollo del transporte o las fuentes de energía) que en su conjunto tendrían al país en un estado de estancamiento respecto de su desarrollo.

\footnotetext{
${ }^{20}$ Ibid p. 10.

${ }^{21}$ Ibid, p. 8.

${ }^{22}$ Ibid, p. 9.
} 
En este aspecto, se hace necesario mencionar que la postura del FRAP es la continuidad de una lectura ya discutida y debatida sobre la realidad económica nacional que se expresa de forma explícita frente al plan de estabilización económica promovido por Ibáñez y la misión Klein-Saks, donde las lecturas y las críticas de la izquierda al plan estabilizador poseen un contenido democrático. En este punto, el plan de estabilización es visto como una política tendiente a disminuir la participación económica de los obreros sobre el ingreso nacional, donde la congelación de salarios, la restricción crediticia y el paso a un régimen de cambio fluctuante aprobados por el gobierno en 1955 afectarían en mayor medida el poder de compra de los salarios más bajos. Para el FRAP, la salida al contexto de crisis es la industrialización, entendiendo que solo así se logra "un desarrollo económico equilibrado y absorber la fuerza de trabajo que anualmente se incorpora a la actividad nacional". ${ }^{23}$ De esa forma, la propuesta del FRAP sostiene que "Una reivindicación urgente e impostergable es cautelar el poder adquisitivo de los sueldos y salarios mediante reajustes adecuados. Hay que barrer con las leyes de congelación y con todo el fárrago de disposiciones tendientes a hambrear a las masas y a castigarlas cuando luchan por el pan". ${ }^{24}$

En términos generales, la política económica del programa de 1958 refleja la oposición al plan de estabilización económica que obedece a un diagnóstico compartido por los partidos que integran el FRAP, entendiendo el programa de estabilización como una política de redistribución poco equitativa y tendiente a la concentración de la riqueza mediante el sacrificio del poder de compra de los sectores obreros y empleados, el cual se vería disminuido por el fin de los reajustes salariales de acuerdo a la inflación anual, en un contexto de sostenida pauperización de las clases obreras. De tal forma, para la izquierda, el gobierno con la asesoría de la misión Klein-Saks habría presentado un proyecto que "demuestra el deseo indisimulado de oprimir a la clase trabajadora y de provocar una redistribución de rentas precisamente hacia los sectores más ricos y poderosos, porque no otra cosa sucederá al congelar los sueldos y salarios dejando libres los precios". 25

Este mismo diagnóstico de la realidad económica se repetiría en 1957, donde el FRAP califica como "antinacional y antipopular" el accionar de los gobiernos de González Videla e Ibáñez, reconociendo una intensificación de la explotación de los trabajadores junto a la reducción de sus salarios reales, el aumento de los impuestos que gravan y la aplicación de medidas que han producido, a juicio del FRAP, una creciente cesantía y llevado a la miseria a miles de hogares, donde el gobierno de Ibáñez es el responsable de dar "cima a esta política entregando los destinos del país a la misión Klein-Saks, con el patrocinio de la cual y la complicidad de la derecha, se dictó una ley de congelación de sueldos y salarios". 26

\footnotetext{
${ }^{23}$ Ibid, p. 26.

${ }^{24}$ FRAP, "Plataforma Programática de la Candidatura Presidencial del Pueblo", p. 5.

${ }^{25}$ Intervención del Senador Rodriguez. Diario de sesiones del Senado. Sesión 25, en 3 de enero de 1956

26 FRAP, "Conclusiones de la conferencia nacional del FRAP. El Frente de Acción Popular y una nueva política para Chile", Boletín del Comité Ejecutivo del PSP, N 14 , enero, 1957, p. 4.
} 
Por otra parte, el proceso de democratización tiene como condición necesaria la reforma del régimen de propiedad. En efecto, entre las medidas políticas para lograr mayor democracia se proclamaba la "consagración de la función social de la propiedad mediante el establecimiento de un régimen legal de dominio y de expropiación". ${ }^{27}$ Probablemente la mayor reforma en este ámbito fue la propuesta de un nuevo régimen de propiedad de la tierra mediante una reforma agraria. Al respecto, el FRAP indicaba que:

La reforma agraria del Gobierno popular constituye un ataque frontal contra toda forma de atraso en el campo; está dirigida a liquidar el poder político y económico de la clase latifundista, construyendo una sólida alianza entre los intereses de los campesinos y las fuerzas de avanzada de la ciudad, terminando con las formas de servidumbre y elevando rápidamente a los factores productivos en el campo. ${ }^{28}$

La necesidad de reformar la propiedad de la tierra tiene un doble objetivo: en primer lugar, lograr el uso eficiente de la tierra arable disponible aumentando las existencias del agro. Pero por sobre todo, desconcentrar el poder mediante la reforma a la propiedad de la tierra, destacando el papel del campesino como actor económico y político válido. De tal modo, es que "la reforma agraria es un imperativo político, económico y social para toda la política progresista y renovadora de la sociedad" ${ }^{29}$, donde sin función social de la propiedad simplemente no habría una democratización plena.

Por otra parte se propone poner fin al latifundio que, además de improductivo, es señalado como el fundamento de la concentración del poder político y económico de las clases propietarias, para lo cual se proponen varios tipos de regímenes de propiedad en su reemplazo con miras a impulsar "el desarrollo capitalista de la agricultura a través de propiedades medianas y pequeñas donde sea técnicamente recomendable; se crearán cooperativas de producción donde se entreguen tierras directamente a los campesinos y se reservará para la explotación directa por parte del Estado aquellos predios en los cuales esta modalidad sea la más adecuada"30. De este modo, el proceso de democratización propuesto programáticamente por el FRAP durante este periodo debe ser entendido como uno que pretende la desconcentración del poder como forma de incluir a las clases subordinadas a la toma de decisiones políticas, haciéndolas participar activamente de todos los aspectos del desarrollo nacional e igualando sus condiciones respecto de los sectores más privilegiados del país, entendiendo como paso previo y obligado de este proceso la democratización de las instituciones y la promoción de una participación equitativa en la renta nacional.

Las elecciones de 1958 darán un resultado sorpresivo para al FRAP al obtener un inesperado segundo lugar. En esas condiciones, la coalición se consolidará a la vez que

\footnotetext{
${ }^{27}$ FRAP, Un camino nuevo para Chile, p. 11.

${ }^{28}$ Ibíd, p. 22.

${ }^{29}$ Idem.

${ }^{30}$ Ibíd, p.23
} 
la década de los 60 verá el desarrollo progresivo de posiciones que comenzarán a articular un discurso revolucionario, poniendo en duda incluso la propia existencia del FRAP como forma viable de lograr los cambios propuestos. ¿Qué permite este cambio en el FRAP? Como veremos a continuación, hay diversos factores que influyen en este proceso. Por un lado, resulta decisivo el contexto político. El éxito de la Revolución Cubana en 1959 servirá como confirmación a los grupos partidarios de una alternativa armada en América Latina, vía que será adoptada por diversos sectores de la izquierda. Igualmente significativa será la adopción del concepto de revolución por parte de la DC, concepto que hasta ese momento, se encontraba fuertemente presente en el discurso de comunistas y socialistas, pero sin llegar a adquirir un peso significativo en los debates políticos públicos, manteniéndose limitado principalmente a las discusiones del interior de la izquierda. La propuesta democratacristiana de una "revolución en libertad" supondrá un desafío directo a los partidos izquierdistas, forzándolos a tomar posiciones explícitas como coalición, y a entrar en un debate hasta entonces inexistente, a saber, cuál era la verdadera opción revolucionaria.

Por otra parte, este nuevo contexto se complementa con elementos propios del socialismo chileno que se encontraban presentes y en constante discusión entre el PC y el PS. La principal discrepancia entre ambos tenía que ver con el carácter de la revolución que proponían, expresados en el Frente de Trabajadores de los socialistas y el Frente de Liberación Nacional de los comunistas. En esta disputa, una cuestión importante era cómo alcanzar el poder y en alianza con quién. El indiscutido carácter electoral y parlamentario del FRAP permitirá que progresivamente, sobre todo luego de 1959, segmentos del PS comiencen a cuestionar la capacidad transformadora de la coalición; a su vez, los comunistas insistirán en la necesidad de consolidar y ampliar dicha estrategia. Así, a medida que cobre importancia la cuestión sobre el cómo alcanzar el poder y la discusión sobre los alcances de la alianza, el concepto de revolución emergerá naturalmente mediante la polémica entre los mismos partidos del FRAP.

De esta forma, la elección de 1964 estará marcada por las tensiones conceptuales dentro del mismo FRAP pero también con varios de los grupos y partidos políticos que reivindican o se presentan a sí mismos como portadores de proyectos reformadores, progresistas o derechamente revolucionarios y subversivos. Como veremos, el FRAP comienza a abordar programática y discursivamente el debate, tomando posiciones que si bien presentan continuidades con el periodo comprendido desde su fundación a la primera elección presidencial, también se diferencian de éste, haciéndose cargo de la experiencia Cubana, la radicalización de sectores de la izquierda, la emergencia del proyecto democratacristiano y las tensiones internas entre la estrategia de la alianza clasista del Frente de Trabajadores del PS y las alianzas interclasistas del Frente de Liberación Nacional del PC. 
El FRAP frente a dos revoluciones: la Revolución en Libertad y la Revolución Cubana en la lectura de la alianza de izquierda.

Poco tiempo después de las elecciones de 1958, el triunfo de la Revolución Cubana vendría a remecer el escenario político para la izquierda. La victoria de los guerrilleros cubanos marcaría un hito para los movimientos revolucionarios de América Latina, y su ejemplo ejercería una influencia significativa en la izquierda del continente. En el caso de Chile, sostenemos que su importancia radica en confirmar las posiciones y estrategias ya existentes al interior de los partidos Comunista y Socialista.

En ese sentido, la Revolución Cubana no sería en sí misma un evento que modificase drásticamente los discursos políticos de los partidos, sino que reafirmará aquellos de tendencia más revolucionaria, permitiendo una mayor radicalización y la consolidación del concepto mismo de revolución. De ambos partidos, el PS fue el más atento a los sucesos desarrollados en Cuba, describiendo ya en abril de 1959 el proceso cubano como "Una caja de sorpresas. Mezcla de romanticismo suicida y locuras geniales, es uno de los hechos más interesantes en el proceso revolucionario latinoamericano", agregando que Cuba "nos ha demostrado que es posible derrotar a un Ejército poderoso (inclusive dirigido desde el pentágono), basándose en las fuerzas y en el heroísmo popular". ${ }^{31}$ En la misma línea, la editorial del primer número de la revista Arauco afirmará que con la experiencia cubana "la revolución deja de ser en nuestros países una mera declaración de propósitos, para convertirse en los hechos una agresión a los intereses dominantes". ${ }^{32}$

Por su parte, el apoyo inicial del PC a Cuba destacará la revolución como símbolo de la lucha de los pueblos latinoamericanos frente al imperialismo. A solo un mes del triunfo de la revolución, Orlando Millas comentaba que la fascinación con Cuba no se debía solo al romanticismo y heroísmo de su revolución, sino también a "que han enfrentado y vencido a enemigos que son también los nuestros y, por lo tanto, sus victorias aparecen como una especie de reivindicación de cada uno de los pueblos latinoamericanos y expresan sus más íntimos y profundos anhelos". 33 Asimismo, se sostendrá que la defensa de Cuba "plantea la lucha antiimperialista en Chile y en el conjunto de la América Latina y la realización de los esfuerzos necesarios a fin de unir y movilizar fuerzas suficientes para obtener un cambio de rumbos en favor de la democracia, del progreso y de la liberación nacional y social en cada uno de nuestros países". 34

Si bien estas reacciones iniciales muestran que el influjo del proceso cubano es innegable para el espectro político chileno, su recepción posterior por parte de la izquierda marca las diferencias existentes entre socialistas y comunistas. En el caso del PS su influencia viene a complementar sus postulados políticos, desarrollados con

\footnotetext{
31 "Cuatro revoluciones en busca de su destino", Boletin del Comite Central del PS N9. abril de 1959, p. 11

32 "Cuba y la conferencia de cancilleres", Arauco, N¹, octubre de 1959, p.6.

${ }^{33}$ Orlando Millas, "La revolución cubana", Principios, Nº54, febrero de 1959, p. 10.

34 “Editorial: solidaridad con Cuba", Principios, N60, agosto 1959, p. 4.
} 
anterioridad al FRAP. Como indica Palieraki, la cercanía de los socialistas con los cubanos se debía principalmente a su tradición tercermundista, latinoamericanista, así como de apoyo a los movimientos de liberación nacional y los postulados antiimperialistas $^{35}$, elementos que se habían ido profundizando al interior de las filas socialistas, permitiendo el surgimiento de postulados de marcado corte revolucionario, los cuales, como observa Luis Ortega, ya se venían perfilando desde la crítica a la experiencia del Frente Popular y la crisis partidaria de fines de la década del 40 e inicios de la década del $50 .^{36}$

La experiencia cubana tendrá repercusiones directas sobre el FRAP. La fuerte simpatía del PS con la revolución lo lleva a criticar directamente el juego democrático institucional bajo el que actuaba la coalición. Por ejemplo el entonces Senador Alejandro Chelén consideraba que una de las enseñanzas de Cuba "es que un movimiento puede comenzar indefinido y amplio y radicalizarse mediante la acción. Es decir, el periodo inicial (...) deja paulatina y gradualmente el paso a los representantes más genuinos de la sociedad"; por ello, para Chelén "en Chile se piensa en forma exagerada en las elecciones, en las luchas parlamentarias, en las controversias legislativas" ${ }^{\text {, }}$. En esta misma línea, Oscar Waiss acusa:

que las directivas de los partidos de avanzada están cayendo cada vez más en las redes del juego de la falsa democracia burguesa, y en que el señuelo de los cargos parlamentarios corrompe a demasiados dirigentes, el ejemplo de la revolución cubana debe destacarse cada día con más vigor. (...) Solo entonces las palabras de Fidel Castro, acerca de convertir a la cordillera de Los Andes en la Sierra Maestra del continente, pasarán a tener su verdadero significado ${ }^{38}$

A diferencia del PS, los comunistas serán cautos con el desarrollo del proceso cubano, cuidándose de no contradecir su línea política. Así, a pesar de apoyar la revolución, el $\mathrm{PC}$ insiste en que el caso de la isla no constituye una experiencia automáticamente replicable en todos los países. Al contrario, a fin de reafirmar su propia posición, el PC argumentará que la victoria revolucionaria en Cuba demuestra que hay que atender principalmente a las condiciones de cada país. De este modo, los comunistas sostendrán que el proceso revolucionario cubano "ha contado con peculiaridades nacionales que corresponden sólo a la realidad cubana. (...) la grandeza de la revolución cubana reside en que se desarrolló, en las condiciones que le eran propias, según el sentido de nuestra

\footnotetext{
${ }^{35}$ Cf. Eugenia Palieraki, ¡La revolución ya viene! El MIR chileno en los años sesenta, Santiago, Lom, 2014 , p. 115.

${ }^{36}$ Luis Ortega, "La radicalización de los socialistas de Chile en la década de 1960", Revista Universum 23:2, pp. 152-164.

37 Alejandro Chelén, La revolución cubana y sus proyecciones en América Latina, Santiago, Ediciones Prensa Latinoamericana, 1960, pp. 36-37.

38 Oscar Waiss. "Cuba: Una experiencia heroica. Las enseñanzas de una revolución”, Cuadernos de información política $N^{\circ} 3.1960$. Ediciones Socialismo, p. 10
} 
época, respondiendo acertada y dinámicamente a cada desafío de las circunstancias."39 Como veremos luego, el caso de los comunistas muestra que, al igual que en el PS, los eventos en la isla son utilizados para reafirmar sus posiciones políticas previas. Más aún, para el PC, esto significará entrar en un debate que hasta el momento no se había visto en la necesidad de enfrentar, a saber, el explicar y justificar qué era lo revolucionario en su línea política.

En consecuencia, mientras el PS toma el ejemplo del caso cubano para confirmar la necesidad de cambios por medios drásticos, el PC deberá realizar un esfuerzo para mostrar que una práctica política totalmente inserta en la institucionalidad existente puede ser auténticamente revolucionaria. Por ello, frente a las posiciones que llamaban a replicar el modelo cubano, los comunistas pondrán énfasis en las posibilidades de la vía pacífica como vía revolucionaria, "convencidos que ser revolucionarios no significa llenarse la boca con la palabra revolución ni soñar con una Sierra Maestra en la Alameda o en el cerro Santa Lucía". 40

En el contexto de los primeros años de la revolución en Cuba, ocurre en Chile otro proceso que impulsa a los miembros del FRAP a debatir en torno al término revolución, esta vez por oposición a una definición rival del mismo. Nos referimos al ascenso político de los democratacristianos y la caracterización de su programa como revolucionario. Los inicios de este proceso ya pueden encontrarse en 1958. En las elecciones de ese año, Eduardo Frei Montalva alcanza un sorprendente tercer lugar con poco más del $20 \%$ de los votos apoyado por la DC, formado tan solo un año antes. En este partido confluían diversos elementos católicos de pasado conservador, agrariolaboristas y falangistas, todos con gran influencia y acervo marcadamente socialcristiano y humanista cristiano como lo demostraría la posición abiertamente reformista y tercerista con la que Frei encaró la campaña. Ésta presentaba como ejes programáticos cambios en el régimen de propiedad, la democratización de buena parte de la institucionalidad vigente, poniendo especial énfasis en las diferencias entre el nuevo programa de cambios con el socialismo, el comunismo y el capitalismo imperante. En esas condiciones, el programa de reformas estructurales ya no sería exclusividad de la izquierda y el uso de la revolución como meta programática tampoco.

La llamada Revolución en Libertad aparece como consigna de un programa de gobierno que da continuidad al afán de reforma a la propiedad, justicia social, democratización y tercerismo presentados en 1958, pero que en los 60 se abre claramente a disputar los significados del proyecto de la izquierda organizada en el FRAP. De este modo, el proyecto de la DC se define como "esencialmente contrario al comunismo. La ideología y las tesis comunistas son incompatibles con la Democracia Cristiana", pero sosteniendo un significado revolucionario "en cuanto quiere cambiar el estilo de la política y hacer

\footnotetext{
${ }^{39}$ Orlando Millas, "Cuatro años de victorias de la Revolución Cubana", Principios, $\mathrm{N}^{\circ} 93$, enero-febrero de 1963 , p. 37.

40 "El discurso de Corvalán sobre las elecciones parlamentarias", Principios, No 79, marzo de 1961, p. 63 64.
} 
profundas transformaciones en el orden existente. Pero su revolución no es violenta, ni de fuerza, sino que pacífica $y$ democrática" ${ }^{\text {"1 }}$. De esta forma, para los democratacristianos la revolución estaba ligada al cambio profundo de las estructuras sociales y económicas propias del capitalismo sin que eso implicara un totalitarismo de corte comunista ni la opresión de ninguna clase por sobre otra, de allí la importancia del adjetivo Libertad, que servirá como diferenciador de las posiciones de izquierda agrupadas en el FRAP, de modo que:

Si en muchos casos la revolución ha significado la pérdida de la libertad y el desconocimiento de derechos básicos del individuo, los cambios sociales y económicos que impulsa el Gobierno del Presidente Frei y su Partido Demócrata Cristiano constituyen una Revolución en Libertad. Ella se realiza dentro de la legalidad democrática, sin abusos, sin arbitrariedades, sin ahogar la libre expresión de ideologías espirituales y políticas. ${ }^{42}$

La cuestión de la libertad tomará vital importancia como elemento diferenciador entre la DC y el FRAP en el contexto de la Revolución Cubana, experiencia de la que los democratacristianos serán especialmente críticos respecto de la adhesión y simpatías expresadas por la coalición de izquierdas con el proceso cubano, acusando que la verdadera pretensión del FRAP es "que el pueblo chileno adopte y acepte los fines y los métodos de la revolución cubana", entre los cuales se contaba la suspensión de la libertades públicas y de los procesos democráticos. Así, el proyecto democratacristiano aparecía como una alternativa revolucionaria frente a "la pretensión totalitaria de la izquierda"; de esta forma se levantaba "La otra vía revolucionaria contra el orden establecido (que) es la de la Democracia Cristiana. Ella se define con la fórmula de revolución en libertad, revolución sin paredón". 43

La críticas desde la DC sobre la actitud del FRAP frente a la Revolución Cubana no terminan allí, pues sostienen que la izquierda no sólo estaría apoyando un proceso revolucionario de corte totalitario, sino que estaría definiendo toda su política respecto a temas internacionales que tienen poca repercusión popular en Chile. Los democratacristianos, sobre todo sus juventudes, leían que "El FRAP se ha quedado rezagado en esta época de cambios y sigue actuando en la misma forma y con el mismo estilo de 20 años atrás. Habla de 'cambios' en general, de la necesidad de efectuar una Reforma Agraria y Tributaria, como pretendiendo convencer al país de cosas que está consciente. El FRAP no ha podido concretar sus ideas y sigue, todavía, haciendo la política de los grandes temas generales" ${ }^{44}$, llegando a decir incluso que los elementos

${ }^{41}$ DC, El ABC de la Democracia Cristiana. Cuadernos de divulgación doctrinaria $\mathrm{N}^{\circ} 1$, Santiago, Editorial del Pacífico, Abril 1962, pp. 28, 30.

${ }^{42}$ DC, Un Programa y un Gobierno, Santiago, Editorial del Pacífico, Febrero de 1967, p. 18.

${ }^{43}$ DC, "La Revolución, la Democracia y el Movimiento Popular", Dice la democracia cristiana a los Partidos Socialista y Comunista, Santiago, Editorial del Pacifico,1963, p.3

${ }^{44}$ JDC, Publicación de la comisión política $N^{\circ} 1$, "La Democracia Cristiana y la revolución en Libertad". Abril 1965. pp. 21-22. 
más moderados de la izquierda tendieron "a quitarle al FRAP el rótulo de 'Revolucionario'" por lo que habría comenzado "a entonar cantos de sirenas a la oligarquía" $"$.

Los dos sucesos hasta acá revisados marcarán un cambio de línea en el aparato discursivo del FRAP. Mientras que la Revolución en libertad obligará a la izquierda el marcar posiciones y distinciones respecto del contenido revolucionario, popular y democrático de la coalición, la Revolución Cubana pondrá en discusión la cuestión de las vías legítimas para alcanzar el poder entre los partidos del FRAP, principalmente dentro del PS y el PC. De aquí en más, las discusiones y debates internos del FRAP se llevarán a cabo en torno al tópico y el concepto de revolución, sus definiciones, características y alcances.

\section{“El cambio no es reforma”: El FRAP hacía la elección de 1964}

Como indicamos anteriormente, los cambios en el contexto político desde fines de los ' 50 vienen a complementar el desarrollo de las discusiones internas en el FRAP, lo que posibilitará la consolidación de "revolución" como concepto central en la configuración ideológica de la izquierda. En ese sentido, puede decirse que dichos eventos no actúan sino como catalizadores del proyecto revolucionario de los partidos del FRAP, el cual ya presentaba un carácter democrático y popular, más no explícitamente revolucionario en sus inicios. Un programa revolucionario era considerado como una fase eventual en el proyecto de la izquierda. Ilustrativo de esta concepción es el discurso realizado por Allende en 1958, en donde clarifica la naturaleza del proyecto del FRAP sosteniendo que "nuestro programa, en esencia, no es un programa socialista, sino uno distinto, en el sentido de que creara las condiciones que permitan un gobierno popular que transforme nuestra democracia anémica, sin vitalidad, sin imaginación, sin sentido ni fuerza creadora". ${ }^{46}$ No obstante, para Allende el programa se considera a la luz de su proyección hacia el socialismo, agregando que "es un proceso de desarrollo generalizado, ya nadie puede imaginarse que, por el deseo de unos cuantos, van a madurar los hechos que marcan la coyuntura de una transformación que signifique la colectivización de los medios de producción". 47 Será entonces esta concepción del programa sustentada en las líneas políticas propuestas por socialistas y comunistas que contemplaban el desarrollo de sucesivas fases para lograr el socialismo, la que permitirá en términos teóricos, entender el desarrollo discursivo del FRAP hacia posturas revolucionarias.

En este aspecto, tanto la revolución cubana como la aparición de la democracia cristiana obligan a plantear en términos revolucionarios el programa del FRAP con miras a la elección de 1964. En las primeras reuniones de la coalición ya se evidencian algunos cambios respecto de las definiciones políticas adoptadas en el periodo anterior, pero

\footnotetext{
${ }^{45}$ DC, “La Revolución, la Democracia y el Movimiento Popular”, p.3

${ }^{46}$ Intervención del Senador Allende. Diario de sesiones del Senado. Sesión 17, en 8 de julio de 1958

${ }^{47}$ Ídem.
} 
manteniendo las definiciones democráticas del programa de 1958. En este sentido, durante el consejo nacional ejecutivo de 1962 se define al FRAP como la única alternativa de poder de los trabajadores y las grandes mayorías nacionales, declarando "la convicción de que la próxima jornada presidencial más que una simple elección del primer Mandatario de la nación, constituirá una consulta plebiscitaria de hondo contenido revolucionario" ${ }^{48}$ y sosteniendo que más allá de lo meramente electoral el compromiso es "fortalecer la acción del pueblo, tanto en el plano político como en los campos económico y social, para frustrar y aplastar las tentativas (...) de los sectores reaccionarios y golpistas, que quieren obstaculizar la utilización de las vías legales, restringir las libertades democráticas e impedir la inevitable victoria de las fuerzas populares". ${ }^{49}$ De esta forma, el FRAP mantiene su compromiso con las vías legales, la democratización y la inclusión de las mayorías nacionales al ejercicio del poder pero ahora otorgándole un contenido revolucionario al cambio propuesto.

Esta adopción del concepto de revolución viene de la mano con el endurecimiento de los diagnósticos respecto de la realidad política que enfrenta la izquierda como representante de las mayorías nacionales. En este aspecto es que el pueblo en su lucha por la emancipación "se enfrenta desde hace años al imperialismo, a la oligarquía terrateniente y al capital monopolista", en un enfrentamiento que si bien no es nuevo si se ha recrudecido como "consecuencia del fracaso del actual gobierno y del régimen económico, político, jurídico y social que actualmente nos rige" ${ }^{\$ 0}$. Producto de lo anterior, es que el FRAP declara la necesidad de instaurar un "Gobierno Popular, nacional y revolucionario, capaz de construir las bases de una verdadera democracia",51

Respecto al alcance democrático, en el programa de 1963 las demandas no difieren drásticamente de aquellas presentadas en 1958. Aun cuando algunas leyes represivas habían sido abolidas y los comunistas habían vuelto a la legalidad, las propuestas continúan centrándose en los aspectos institucionales del ejercicio democrático, buscando principalmente asegurar una mayor participación popular. Por ello, el contenido democrático se define "como una responsabilidad directa, consciente, permanente y orgánica del pueblo en los asuntos públicos", haciendo efectiva "la participación de las fuerzas laborales en las grandes tareas del país". ${ }^{52}$ En cuanto a la concretización de este proceso de democratización, y a diferencia del 58, el programa no lista en detalle las medidas más allá de las reformas a las instituciones estatales. No obstante, la cuestión de la democracia y sus alcances continúa siendo fundamental para comprender el carácter transformador y progresivamente revolucionario del FRAP.

Resulta especialmente relevante la continuidad de la asociación entre democracia y cuestiones de índole económica y social. Para la coalición, la democratización debía

\footnotetext{
48 “Importante reunión del FRAP en Las Vertientes", Arauco. N²5, 1962, p 18.

${ }^{49}$ Íbid, p 19

${ }^{50}$ FRAP, "Programa presidencial del Frente de Acción Popular", Arauco. N³6, 1963. p 7.

${ }^{51}$ FRAP, "Acta de proclamación del Candidato Presidencial del Pueblo Dr. Salvador Allende", Arauco. $\mathrm{N}^{\circ} 36.1963 . \mathrm{p} .5$

${ }^{52}$ FRAP. Programa del Gobierno Popular, Santiago, Impresora Horizonte, s/f, p. 14.
} 
pasar por la inclusión de los sectores populares en los diversos ámbitos de la vida social, postulando “(...) la sustitución de un régimen excluyente por un régimen participante en que la inmensa mayoría de los que en la actualidad quedan marginados de importantes aspectos de la vida nacional, se incorporen plenamente al nuevo sistema social". 53 Concretamente esto significaba una serie de medidas destinadas a asegurar el efectivo reconocimiento del pueblo en la actividad económica y productiva, en sus organizaciones sindicales y locales, y de una protección de sus derechos laborales, sociales y económicos. ${ }^{54}$

En la relación entre economía y democratización, un ámbito que ve aumentada su importancia es la reforma agraria, dado que se le considera “(...) la condición previa más importante de nuestro desarrollo económico y social, que consiste, precisamente, en la liberación de la energía y potencialidad creadoras de las masas rurales, las que han sido contenidas y oprimidas por siglos de opresión y servidumbre degradantes". ${ }^{55}$ Más aún, la reforma agraria resulta crucial en el nuevo contexto político debido a las diferenciaciones que realiza el FRAP con la DC. En este sentido el FRAP se pronuncia explícitamente diciendo que hará la auténtica reforma agraria tendiente a transformar el régimen de propiedad, las formas de trabajo de la tierra y de explotación agropecuaria. En este aspecto para la izquierda se vuelve imperativo comenzar a tomar distancias y posiciones frente al proyecto democratacristiano:

(...) la reacción y su nueva cara -la Democracia Cristiana- han desatado
una millonaria campaña publicitaria de calumnias, destinadas a
desvirtuar los puntos de vista del Movimiento Popular (...) en el
problema agrario la reacción ha sido especialmente hábil para frenar y
desvirtuar los cambios que ya no son posibles de eludir. En efecto,
expresiones como 'cambios estructurales', 'reforma agraria',
'redistribución del ingreso', etc. han sido incorporadas al vocabulario
propagandístico de la reacción. Ya se ha hecho imposible atacar al
Movimiento Popular denunciando sus planes programáticos como
demagógicos e irrealizables, y se ha tornado necesario recurrir a
nuevas fórmulas.

Más allá de las nociones prácticas sobre la reforma agraria, el FRAP se diferencia de manera conceptual del proyecto de la Revolución en Libertad mediante el concepto mismo de revolución que propone, el cual está estrechamente ligado al de democracia, de modo que, para la izquierda la revolución implica el cambio profundo de las estructuras existentes acabando con el sistema de injusticias y dominación imperante a través de un proceso de democratización e inclusión mediante la planificación popular, poniendo especialmente énfasis en el carácter y alcance del cambio. Para el FRAP "El

\footnotetext{
53 OCEPLAN. Las primeras 100 medidas del Gobierno Popular, Santiago, Impresora Horizonte, 1964, p.17.

${ }^{54}$ Ibíd, pp. 17-19.

55 "Ideas fundamentales para una reforma agraria. Tesis aprobada en la conferencia de Programa del FRAP", Arauco. $\mathrm{N}^{\circ} 46,1963$, p.15.

${ }^{56}$ OCEPLAN, La política Agropecuaria del Gobierno Popular, Santiago, Impresora Horizonte, 1964, p.5
} 
cambio no es reforma, ya que él va a los sustantivo en tanto que la segunda se queda en los aspectos formales" donde lo que se pretende es "que la inmensa mayoría de los que en la actualidad quedan marginados de importantes aspectos de la vida nacional, se incorporen plenamente al nuevo sistema social". 57

Justamente este punto, el carácter del cambio y sus alcances, será fundamental para comprender las diferencias con un proyecto democratacristiano, que a la luz de los juicios del FRAP es de carácter reformista y reaccionario, mas no revolucionario. En este sentido, el programa popular, democrático, nacional y revolucionario que pretende el FRAP implica "realizar los cambios revolucionarios que den forma y contenido a una nueva convivencia social. No se trata de transformaciones insustanciales en lo político" pues la lucha de la izquierda es "por nuevas estructuras económicas y políticas" que deben ser entendidas como un programa de cambio sustantivo de la realidad nacional, y no como iniciativas separadas y orientadas a problemas y demandas específicas. ${ }^{58}$

Sin embargo, y pese a que el FRAP habla directamente de cambios revolucionarios, es necesario dejar en claro que el concepto aparece en función del cambio de estructuras y no apelando a la violencia revolucionaria de manera directa ni al cambio radical de las mismas. En este aspecto el programa reconoce que el "único camino que queda abierto es el ataque a fondo, el cambio revolucionario, entendiéndose por tal la transformación profunda del estado actual" ${ }^{\text {" }}$, pero reconociendo que el cambio no se trata de la instauración rápida y violenta de un sistema socialista, entendiendo que el programa de cambios implica un periodo de transición para la resolución estructural de los problemas nacionales, donde la violencia aparece inclusive como una posibilidad que debe ser evitada en la lucha por la conquista del poder. En palabras del propio Allende: "o conquistamos nosotros el poder por los cauces legales y realizamos las profundas y serias transformaciones que la nación necesita o este país, tarde o temprano, va a verse abocado a una lucha fratricida". ${ }^{60}$ Para el FRAP es el contenido y alcance de los cambios los que vuelven su programa uno de carácter revolucionario, donde el contenido democrático es fundamental en tanto permite acabar con el orden hasta entonces existente mediante la entrada de los sectores antes excluidos a los espacios del poder.

Resulta importante destacar que las visiones sobre la conquista y la disputa por el poder que presenta el FRAP como coalición se distinguen de la experiencia cubana y también de la discusión interna entre socialistas y comunistas sobre el tópico de las vías revolucionarias. Como vimos anteriormente, las expresiones de aprobación, simpatía y solidaridad con el proceso cubano son compartidas tanto por los partidos miembros de la coalición como por el FRAP mismo. En este sentido, la reunión en Las Vertientes en 1962 ya proponía la salida de Chile de la OEA en solidaridad con Cuba, la cual es reafirmada en el mismo programa de gobierno para la campaña de 1964 como parte de

\footnotetext{
${ }^{57}$ FRAP, Programa del Gobierno Popular, p.13

58 “Allende: pensamiento y acción”, Arauco, №50, 1964, p. 48

${ }^{59}$ Ibid, p. 12

60 “Allende: pensamiento y acción”, Arauco, N50, p. 14
} 
una lucha común por lograr la plena emancipación de los pueblos frente al imperialismo. Sin embargo, la radicalización impulsada por los hechos de la Revolución Cubana, sobre todo al interior del PS, implicó que la discusión en torno a la idea de la revolución y sus alcances se centrará cada vez más en el tópico de las vías revolucionarias, sobrepasando eventualmente a las definiciones mismas sobre lo que implicaba la revolución en término de transformaciones al orden existente.

Lo anterior tendrá efectos directos en el FRAP a medida que se acercan las elecciones de 1964, pues los debates en torno al tema implicarán escisiones internas y profundizarán las posiciones de cada partido. En el ámbito discursivo, el efecto más significativo será que, en términos conceptuales y lingüísticos, "revolución" pasará a ocupar un lugar central en la configuración ideológica de la izquierda en tanto servirá como puente entre el resto de sus componentes ideológicos y el contexto político del momento. De esa manera, y a diferencia de los inicios del FRAP, tras la derrota de 1964 todos los debates en la izquierda pasarán, necesariamente, por la cuestión de la revolución, sus alcances, sus formas y su contenido.

\section{El espejismo del 64: el FRAP entre comunistas y socialistas tras el fracaso electoral}

Las discusiones al interior del FRAP a partir de la derrota electoral de 1964 estarán marcadas en el seno de sus partidos por importantes procesos de revisión y autocrítica en el caso del Partido Socialista; y, en el caso del Partido Comunista, por los intentos de formar una línea política que permita la apertura al centro si se quiere lograr alcanzar al poder por las vías electorales. Al mismo tiempo, el influjo del discurso "revolucionario" de la DC además de la Revolución Cubana, vuelve inevitable que la discusión y el debate en el seno de ambos partidos sea determinado por la palabra y la idea de la revolución, volviéndose un tópico de carácter ineludible en las diversas instancias partidarias y conjuntas del FRAP hasta su fin en 1969.

Como mencionamos antes, la radicalización de un discurso revolucionario será especialmente relevante dentro del PS, que incluso antes de la derrota electoral de 1964 entra en un proceso de revisión y discusión interna que termina en la expulsión de elementos trotskistas y la salida de dirigentes juveniles durante el XX congreso general ordinario del partido, quienes tras el voto político aprobado en la instancia acusarán la desradicalización del PS y su distancia con el marxismo leninismo, participando posteriormente en la fundación del MIR. ${ }^{61}$ Dicho congreso tendrá como principal tema la ratificación de la línea política frapista, la discusión sobre la unidad del movimiento popular y del partido, y la diferenciación conceptual e ideológica de la izquierda respecto del proyecto revolucionario de la DC. En este último punto, en su informe al Congreso como secretario general, Raúl Ampuero declara que la oposición común del PDC y el FRAP al gobierno de Alessandri "había creado la sensación de que entre el FRAP y la

\footnotetext{
${ }^{61}$ Julio César Jobet, El Partido socialista de Chile, Tomo II, Santiago, Ediciones Prensa Latinoamericana,
} 1971. 
Democracia Cristiana existían analogías estrechas, susceptibles de reflejarse en un entendimiento presidencial"62, pero acusando que "la 'Revolución en Libertad', el 'Régimen comunitario’ ¿qué son sino consignas demagógicas y vacías?”, y que tras el "slogan” democratacristiano había un "fraude político, como la 'Revolución' de Hitler, como la 'Revolución' de Franco. Una audaz tentativa de preservar los privilegios bajo la cobertura de una política innovadora". 63

Sin embargo, antes del XX Congreso ya se habían vivido algunas de las salidas polémicas que expresaban los desacuerdos respecto de la línea política frapista al interior del PS. Particularmente bullada fue la expulsión en 1961 del dirigente y militante Oscar Waiss, quien fuera representante de las líneas "revolucionarias" dentro del partido desde su ingreso a la militancia socialista en 1936, proveniente de la Izquierda Comunista y cercano a Manuel Hidalgo Plaza. Waiss fue quizás uno de los más activos polemistas dentro del partido, siendo particularmente crítico de la administración de Raúl Ampuero y de la vía electoralista para alcanzar el poder. Al respecto, en 1962 sostenía que "el FRAP se ha dejado coger en el juego que le conviene a la burguesía y el imperialismo, el juego de la democracia formal y de las pugnas electorales", y que a su juicio la línea frapista "...significa lisa y llanamente, renegar de la orientación revolucionaria del socialismo chileno y regresar a una versión criolla de la vieja social-democracia europea" ${ }^{\text {64 }}$. Una vez consumada la derrota del FRAP en 1964 el mismo Waiss dirá que "Los trabajadores chilenos han vivido, prácticamente durante los últimos dos años, en pos de una esperanza absurda inflada por los comités centrales de los partidos en que ellos se encuentran organizados", agregando que "Los dirigentes responsables de la derrota -de la inevitable derrota- tienen que ser singularizados y aventados, sin que una falsa lealtad hacia ellos ciegue a los que tienen en sus manos la responsabilidad de castigar la traición". 65

En medio de estas tensiones internas, la victoria de Frei implicó para los socialistas una reacción que se materializa en un proceso de autocrítica y cambios, que incluso adelantó la fecha prevista para la realización del XXI Congreso General Ordinario y detonó que Ampuero no se presentará a la reelección como secretario general. A la crítica del electoralismo por Waiss y algunas facciones más radicales de las juventudes del PS solo un año antes, ahora se sumaban las críticas de algunos miembros de la dirección. Mientras Ampuero admitía que "el gran error de la izquierda (fue) el haber estimado al Frente Democrático como el enemigo principal", llevando al FRAP a "otorgar a la DC un trato de aliado eventual, subrayando cada vez la comunidad de intereses de las fuerzas de oposición frente al gobierno de Alessandri" ${ }^{66}$, Adonis Sepúlveda, como secretario general, presentaba una tesis política novedosa para convertir al Partido en una "herramienta revolucionaria" mediante reformas al mismo, reafirmando la línea política

\footnotetext{
${ }^{62} \mathrm{PS}$, 1964: año de prueba para la revolución chilena. Informe del Secretario General al XX Congreso del Partido Socialista, Santiago, Ediciones Prensa Latinoamericana, 1964, p 16.

${ }^{63}$ Idem.

${ }^{64}$ Oscar Waiss, El espejismo del 64, Santiago, Imprenta Victoria, 1962, p.4.

${ }^{65}$ Oscar Waiss, Basura teórica y traición política, Ediciones el Gallo Rojo, 1964, p.1

${ }^{66}$ Informe del Secretario General del Partido Socialista al XXI Congreso General Ordinario. 1965. p.7
} 
del frente de trabajadores y asumiendo que la institucionalidad como única vía "significó crear falsas ilusiones con respecto a la forma de llegar al poder e impidió por una etapa la liquidación del régimen imperante". ${ }^{67}$

Así, la crítica de los socialistas al FRAP tiene que ver con la preponderancia de las vías institucionales para alcanzar el poder. Para éstos, la derrota electoral de 1964 demostraba la imposibilidad de hacerse con el poder político únicamente mediante las urnas. Se hacía necesario entonces construir un partido que estuviese a la vanguardia del movimiento popular para su conducción en el enfrentamiento decisivo entre clases, pues sólo así se aprovecharía el potencial revolucionario de las masas con miras a la resolución final de la diada "capitalismo/socialismo" en el nuevo escenario abierto por la "demagogia" democristiana y su revolución en libertad.

En esta misma línea, el PS exponía su posición al XII Congreso del PC que:

(...) al no haber orientado la lucha social hacia un enfrentamiento decisivo de clases y al haber encajonado el ascenso del movimiento popular dentro del mecanismo jurídico de la burguesía, convirtiendo esta lucha en el camino propio de la Revolución Chilena, en los hechos dejamos la lucha popular chilena sin otra salida momentánea que el triunfo electoral. La derrota produjo su estagnamiento y creó una nueva situación política. ${ }^{68}$

Por ello, el proceso de radicalización iniciado por el PS consiste en último término en la ratificación de la línea estratégica del Frente de Trabajadores y las posturas de clase dentro del FRAP pero con un marcado viraje lingüístico desde el reformismo y el progresismo a la revolución propiamente tal. A su vez, estas posturas implican una fuerte crítica a la vía puramente institucional al reafirmar la condición clasista de la alianza frente a la estrategia comunista, proceso que alcanzará su momento culmine durante el XXII Congreso General Ordinario de Chillán en noviembre de 1967.

En este punto el PS “denuncia la táctica del Frente de Liberación Nacional, (que) llamando a la burguesía progresista a unirse con las clases trabajadoras en la lucha contra el capitalismo", considera como "una contradicción con cualquier posición antiimperialista y una carencia de identidad de intereses entre esa consigna y las clases trabajadoras"69. Esta actitud, tuvo su manifestación más clara al declarar la negativa de su apoyo partidario a la candidatura del radical Alberto Baltra en una elección complementaria, inclusive cuando el resto de los partidos del FRAP lo hicieron, señalando sobre este hecho en el congreso de Chillán que La incorporación del Partido Radical debilita al FRAP "engendrando y robusteciendo en ella toda suerte de ilusiones

\footnotetext{
67 Julio César Jobet, op. cit, p. 112.

${ }^{68}$ Aniceto Rodríguez, "Al Partido Comunista en su XIII Congreso General Ordinario. Franqueza en las relaciones de dos partidos marxistas", El socialismo y la unidad. Cartas del Partido Socialista al Partido Comunista, Santiago, Prensa Latinoamericana, 1966, p.9

${ }^{69}$ Julio César Jobet, “Algunos problemas teóricos del socialismo”, Arauco, N88, 1967, p.72
} 
electoralistas que la experiencia ha demostrado ser absolutamente inconducentes para desencadenar un proceso revolucionario dirigido a la toma del poder" más aún "cuando las elecciones se realizan con el fin principal de conseguir mayor número de votos, aspiración que es contradictoria con el propósito de fortalecer orgánica, ideológica y políticamente el movimiento popular". 70

Paralelamente, dentro del proceso vivido al interior del PC, el término revolución no parece alcanzar por sí mismo la importancia conceptual que desarrollará su aliado socialista. Posterior al año 1958, el PC publica el Programa de 1962, que constituye una actualización de aquel de 1956. A diferencia de este último, el Programa del 62 da mayor centralidad a la revolución, cuestión que sin embargo se encuentra estrechamente ligada a su política de liberación nacional y que, para definir su contenido, recurre de manera constante a los conceptos de democracia y democratización. Así, el Programa afirmaba que la democratización "es la clave para desatar ampliamente las fuerzas creadoras del pueblo y para garantizar el cumplimiento de las tareas de liberación". ${ }^{71}$ En lo relativo directamente al tópico de la revolución, el Programa le dedica un apartado significativo. Allí, además de reiterar la importancia de la unidad de las clases populares y la unidad antiimperialista, expresada esta última en la colaboración con otros partidos y el FRAP, se aborda también la cuestión de las vías revolucionarias. Las definiciones dadas en este punto resultan relevantes en tanto se expresan en términos similares a las dadas por documentos previos del FRAP. Echando manos al carácter transformador del proyecto de la izquierda, se sostiene que el resurgimiento de Chile no es posible "sin las transformaciones de la estructura económica y el desarrollo democrático que implican en sí mismos un proceso revolucionario", agregando que dicho proceso será una revolución "porque reemplazará a las clases en el poder, renovará a fondo el aparato estatal y eliminará las relaciones de producción que entraban el desarrollo de las fuerzas económicas sustituyéndolas por otras de carácter progresista". ${ }^{72}$

Lo significativo de esta formulación es que, si bien el carácter democrático de la política del PC se encontraba fuertemente presente en su programa anterior, la aparición cada vez mayor del concepto de revolución implica que los comunistas deben entrar en un proceso de clarificación conceptual que hasta entonces no parecía necesario. Así, una vez que el concepto y tópico de la revolución aparece abiertamente como una cuestión en debate, el PC debe comenzar a dar sentido a su discurso previo, haciéndose cargo del progresivo carácter revolucionario del proyecto izquierdista. Para los comunistas, este proceso de conceptualización se tornará más complejo a medida que se acercan las elecciones de 1964. Las implicancias de ello son dobles. Por un lado, los constantes debates con el PS, que a pesar de su adhesión al FRAP ostenta una retórica abiertamente revolucionaria, llevan a los comunistas a incorporar el concepto de revolución a un discurso centralmente democratizador, expresado en la propuesta de una vía pacífica al socialismo. El resultado es que revolución parece fundarse de manera importante en

\footnotetext{
${ }^{70}$ Julio César Jobet, op. cit, pp. 128-129.

${ }^{71}$ PC, Programa del Partido Comunista de Chile, Santiago, Impresora Horizonte, 1962, pp. 35-36.

${ }^{72}$ Ibíd, p. 40.
} 
nociones democráticas, lo que se complementa con el camino adoptado por el FRAP. Por otro lado, el mismo proceso lleva a que, de manera similar a lo que va ocurriendo con el PS, el concepto de revolución se consolide como el término principal para expresar su proyecto político, al punto de que tras las elecciones de 1964 el proyecto del FRAP se torna indiscutidamente revolucionario por la centralidad que dicho término ocupa. Este proceso se puede notar en los debates en torno a las vías revolucionarias, que en el caso de los comunistas resulta en un intento de clarificar por qué la vía pacífica sería efectivamente revolucionaria.

Ejemplo de lo anterior es un texto publicado en 1961, donde Luis Corvalán se aboca a defender la política de la vía pacífica que había sido promovida por el PC desde 1956. En primer lugar, resulta interesante notar que existe en las formulaciones de Corvalán una estrecha ligazón entre la vía pacífica y un proyecto democrático. Al respecto, afirmaba que teóricamente la vía pacífica era posible también en aquellos países donde no se planteaba aún una revolución socialista, "sino la revolución democrática o, simplemente una revolución nacional libertadora". 73 Esta idea cobra más fuerza considerando que ese mismo año Corvalán había definido la revolución propugnada por el PC como una "revolución democrática, popular y nacional, anti-imperialista, antifeudal y antimonopolista. No se trata, pues, de la revolución democrático burguesa según la concepción clásica, sino de una revolución democrática y popular de nuevo tipo". 74 El problema para los comunistas parece presentarse al tener que hacerse cargo de las interpretaciones más radicales de la izquierda que proclaman abiertamente formas violentas de revolución. La salida para Corvalán es argumentar que la vía pacífica se refiere solamente a "la posibilidad de cambios revolucionarios sin recurrir a la insurrección armada o a la guerra civil, y no estamos descartando otras posibles formas de violencia en menor escala". ${ }^{75}$ Mediante esta definición, los comunistas intentaban hacerse cargo del creciente impulso de un proyecto revolucionario que en su definición parecía incluir necesariamente la violencia. No obstante, a pesar de las explicaciones dadas por el secretario general comunista, la idea de la violencia revolucionaria no parece ser en ningún caso definitoria de lo que el partido plantea como proyecto político, pues para ellos su carácter revolucionario no parece jugarse en la presencia de formas violentas de lucha.

Al contrario, como bien ha demostrado Álvarez, ${ }^{76}$ el concepto decisivo en el ideario comunista es la lucha de masas, entendida como una constante labor de agitación, organización y reivindicación de los sectores populares y sus demandas, permitiendo así una articulación entre prácticas "reformistas" (elecciones, parlamento, municipios) y "revolucionarias" (tomas, huelgas, agitación popular). Así, el discurso del PC se

\footnotetext{
${ }^{73}$ Luis Corvalán, “Acerca de la vía pacífica” (1961), Camino de Victoria, Santiago, Impresora Horizonte, 1972, p. 27.

74 "Intervención de resumen del camarada Luis Corvalán en el Pleno del Comité Central", Principios, 1961, No 87 , noviembre-diciembre, p. 51.

${ }^{75}$ Luis Corvalán, op cit., p. 34

${ }^{76}$ Rolando Álvarez, Arriba los pobres del mundo .Cultura e identidad del Partido Comunista de Chile entre democracia y dictadura. 1965-1990, Santiago, Lom, 2011, capítulo 2.
} 
enfocará en resaltar el impulso de las masas, proponiendo un fortalecimiento de la unidad entre las clases populares e incluir en la lucha a la mayor cantidad de fuerzas progresistas. Serán justamente estos elementos los que desde 1956 se consideran como centrales para determinar las reales posibilidades de la vía pacífica, los que se mantienen constantes durante el periodo previo a las elecciones de 1964. Como reafirmaba Corvalán ese mismo año, asegurar el camino pacífico implica hacer imposible que los reaccionarios "desencadenen la violencia", y que para ello "lo más importante (es) desarrollar el movimiento popular, las luchas, la organización, la unidad y la consciencia (sic) política de las masas". 77

Esta revisión a las elaboraciones teóricas del PC permite comprender mejor la continuidad y el grado de ruptura de su discurso y lenguaje político tras 1964. Por una parte, Álvarez ha identificado que el término vía pacífica es abandonado tras 1964, siendo reemplazado por el de vía no armada. ${ }^{78}$ Este último parece resolver el problema de aquellas formas de lucha que, excediendo los marcos institucionales, se presentan como revolucionarios pero que, a la vez, resultan de difícil asimilación en términos discursivos por la línea política del PC. Así, aunque conceptualmente no existen mayores modificaciones para los comunistas, dicho cambio denota la consolidación que venía experimentando la radicalización del concepto revolución, y que ya se levantaba como el término central para definir el proyecto de la izquierda a pesar de las divergencias existentes entre socialistas y comunistas.

Por otro lado, hay en el PC una continuidad manifiesta de sus principales conceptos que el fracaso electoral no logra alterar. El fortalecimiento y unidad antiimperialista, así como de las masas populares y la amplitud de las luchas locales como forma de avanzar hacia el socialismo predominan en su discurso. Ejemplo de aquello es la respuesta de Corvalán a una carta crítica del PS en 1966. Allí, el dirigente comunista insistía en que la línea del Partido se distingue "por su amplitud, por tener en cuenta los diversos grados de desarrollo político de las variadas y vastas fuerzas que pueden y deben participar en esta lucha (antiimperialista)". ${ }^{79}$ En concreto, la amplitud propuesta por el PC se enfoca hacia los sectores populares que habían apoyado a la DC.

Por lo anterior, es que Corvalán añadía que el principal problema para comunistas y socialistas era cómo liberar a dichos sectores de lo que consideraban era la influencia burguesa de los democristianos, cómo "ganarlos para las posiciones del FRAP, demostrarles que ustedes y nosotros somos los luchadores más consecuentes por los intereses del pueblo y que juntos constituimos la única fuerza capaz de hacer realidad los cambios revolucionarios". ${ }^{80}$ Esta interpretación se profundiza en la misiva, llegando a sostener que las posiciones anticapitalistas dentro del PDC demostraban la influencia de

\footnotetext{
${ }^{77}$ Luis Corvalán, “Aseguremos el camino pacífico”, Camino de Victoria, Santiago, Impresora Horizonte, 1972, pp. 74-75.

${ }^{78}$ Álvarez, op. cit., p. 79.

${ }^{79}$ Luis Corvalán, Nuestros caminos conducen al socialismo. Respuesta del Partido Comunista de Chile al Partido Socialista, Santiago, Impresora Horizonte, 1966, p. 2.

${ }^{80}$ Ibíd, p. 3.
} 
las ideas socialistas, y que por tanto la obligación era "comprender que las masas convergen al socialismo sin recorrer todas el mismo camino", y que a pesar de la política del Frente de Trabajadores era necesario tender una mano a los "trabajadores democratacristianos, como igualmente a los trabajadores radicales". ${ }^{81}$ De esta forma, aunque la revolución se manifiesta como el objetivo principal, la línea de los comunistas permanece inamovible en lo esencial al subrayar la unidad y la lucha de masas, al punto que, como sostiene Furci, llegará a ser la tesis predominante al momento de conformar la UP. ${ }^{82}$

Lo cierto es que a partir de 1964 los procesos descritos hasta ahora tendrán efectos decisivos para el FRAP. La presencia de un fuerte partido de centro con características programáticas que disputará la base social de apoyos de la izquierda e incluso su programa de transformaciones, como fue el caso de la DC y su "revolución en libertad", presentó un importante desafío para el FRAP. Para hacer frente a dicha situación, los partidos que componen la coalición izquierdista se ven en la necesidad de marcar distancia de la DC, obligando a la toma de posiciones y definiciones ideológicas que explicitarán los contenidos y diferencias del programa frapista con el democratacristiano. Revolución se convirtió en el término en disputa no solo por su apropiación por parte de la DC, sino porque además permitiría a comunistas y socialistas reafirmar las particularidades de su proyecto, llevándolos a profundizar, y en algunos casos a radicalizar, sus definiciones para superar la derrota de 1964. Sin embargo, este proceso de diferenciación tiene el efecto de reflotar, una vez más, las diferencias entre el PC y el PS. Como mencionamos anteriormente, dicha diferenciación ya se había evidenciado con el influjo de la Revolución Cubana, producto del cual cada partido ya había reafirmado sus líneas políticas. Esta vez, a los debates en torno a los alcances de la alianza electoral del FRAP, se suma un proceso de radicalización socialista como forma de resistencia a la apertura comunista con el centro y de profundización de la influencia cubana. Como resultado, es posible sostener entonces que el proceso de reafirmación del contenido revolucionario en la izquierda como una forma de distanciarse del PDC y la simultanea diferenciación que esto produce entre el PC y el PS, termina por debilitar el discurso inicial del FRAP como coalición, adquiriendo mayor importancia el debate interno sobre cuál política y estrategia a seguir en la disputa por el poder con un contenido y programa revolucionario.

\footnotetext{
${ }^{81}$ Ibíd, pp. 3-4.

${ }^{82}$ Cf. Carmelo Furci, The Chilean Communist Party and the Road to Socialism, Londres, Zed Press, 1984. Cabe mencionar que, aunque el Frente de Liberación Nacional cae progresivamente en desuso desde fines de los '50, los postulados que contiene bien pueden considerarse como la base de la línea política del PC a lo largo de la década de 1960. En efecto, el carácter antiimperialista, antioligárquico y antimonopolista, del Programa de 1956, así como la política de alianzas interclasistas, son reafirmadas en 1962 e incluso en el Programa de 1969, en donde se sostiene que "sus tesis fundamentales son las mismas que se elaboraron y aprobaron en el Décimo Congreso Nacional, efectuado en marzo de 1956". PC, Programa del Partido Comunista de Chile, Santiago, Impresora Horizonte, 1969, p. 3. Ver también Hernán Venegas, "El Partido Comunista de Chile: antecedentes ideológicos de su estrategia hacia la Unidad Popular (1961-1970)", Revista de Historia Social y de las Mentalidades, N7, vol. 2, 2003.
} 
Así, a partir de la derrota frapista en 1964 y en particular después de 1967, cuando los comunistas y el resto del FRAP, con excepción de los socialistas, apoyan la candidatura del militante radical Alberto Baltra, las posiciones del Frente de Trabajadores, que habían mantenido al FRAP como una coalición sólo de partidos marxistas serán reemplazadas por la tesis comunista emanada del Frente de Liberación Nacional. Como resultado, el FRAP terminará por abrirse a parte del centro político definitivamente en 1969, dando paso a la fundación de la UP, pero también marcando un giro lingüístico y discursivo que pone definitivamente en el centro del proyecto común de la izquierda el tópico de la revolución, sin que aquello implique el fin de las diferencias y debates internos entre socialistas y comunistas.

\section{Consideraciones finales}

Hemos desarrollado hasta aquí una hipótesis que se diferencia de los trabajos anteriormente revisados en tanto matiza el contenido revolucionario del programa conjunto de la izquierda chilena durante el periodo del Frente de Acción Popular. Lo anterior debe ser entendido en la lógica de la trayectoria política e ideológica tanto de los partidos socialista y comunista como del propio FRAP, en tanto la aparición del debate y el desarrollo de contenidos discursivos, programáticos e ideológicos propiamente revolucionarios es progresivo y obedece tanto a los procesos electorales y sus resultados, como a los debates en el seno de los partidos de izquierda. El matizar los contenidos revolucionarios del programa frapista no implica negar la presencia del concepto de revolución, sino más bien reconocer, mediante la revisión de las fuentes disponibles, la presencia previa de un proyecto democratizador, transformador y progresista, que va adquiriendo significados revolucionarios durante la década de los sesenta.

Respecto a lo anterior, nos parece relevante esbozar algunas consideraciones relacionadas al caso estudiado, con el fin de comprender mejor el desarrollo de las ideologías políticas y los conceptos que éstas integran. Principalmente nos interesa destacar que éstos últimos nunca se presentan como un conjunto estático de significados, sino que por el contrario, reflejan usos sociales e históricos del lenguaje. ${ }^{83}$ Por ello, debido a que las ideas y conceptos se encuentran inmersas en la realidad, éstas se ven determinadas tanto por razones históricas, como por condiciones culturales o eventos contingentes. Como hemos visto, en el desarrollo del proyecto izquierdista impulsado por socialistas y comunistas, una serie de factores y condiciones contextuales impulsaron a que, progresivamente, el concepto de revolución comenzará a abarcar significados que anteriormente se expresaban principalmente mediante un lenguaje que giraba en torno a una transformación y democratización profunda que excedía los ámbitos formalmente políticos. Por cierto que ese proceso se nutrió de una base lingüística preexistente, en tanto ambos partidos de izquierda habían logrado consolidar un conjunto relativamente común de conceptos tomados principalmente del marxismo, en el que la idea de la revolución ocupaba un sitial significativo mas no necesariamente predominante.

\footnotetext{
${ }^{83}$ Freeden, op cit., pp. 52-53.
} 
Resultan fundamentales en este proceso las trayectorias ideológicas de los partidos Socialista y Comunista así como los procesos de definición común a propósito de los hechos antes descritos. Tanto el influjo cubano como la aparición de la "revolución en libertad" democratacristiana contribuyeron a definiciones ideológicas, políticas y estratégicas en el seno de ambos partidos que influyeron de manera decisiva en los contenidos y programa del FRAP. Las diferencias entre socialistas y comunistas pesan en las definiciones iniciales del proyecto transformador, progresista y democratizador en tanto la línea del "Frente de Trabajadores" como la del "Frente de Liberación Nacional" proponen consideraciones estratégicas e ideológicas encontradas para la conducción de la alianza de izquierda. Si bien buena parte de los debates en el seno del FRAP se verifican en el encuentro de estas dos líneas estratégicas, también existen discusiones que ponen sobre la mesa las características mismas de la alianza, sobre todo desde el PS, que propone una revisión crítica del carácter eminentemente electoral de la izquierda sobre todo después de la elección de 1964.

En términos más explícitos, creemos que el proceso de radicalización discursiva que permite el paso de un proyecto progresista a uno revolucionario está dado particularmente por procesos que ocurren a nivel de militancias internas, siendo el PS especialmente receptivo a este tipo de discursos y posiciones, sobre todo luego del influjo de la Revolución Cubana y la derrota electoral de 1964. El FRAP, como proyecto conjunto de la izquierda chilena, adquiere significados y discursos revolucionarios de manera tardía, haciéndose particularmente presentes y evidentes luego de 1964, proceso que está acompañado por el abandono de la estrategia clasista propuesta por las tesis del Frente de Trabajadores y la apertura al centro -no sin la resistencia de un radicalizado PS- propuesta por la línea comunista, la que a la postre terminaría adoptando la alianza de izquierda de manera oficial a partir de 1969 luego de la fundación de la UP. Esta última, a diferencia del programa anterior, estará caracterizada por la presencia de un proyecto democratizador y de transformación que se identifica desde sus inicios como eminentemente revolucionario.

Entendemos y somos conscientes de que el debate entre socialistas y comunistas no se agota en las diferencias existentes en torno a las líneas del Frente de Trabajadores y del Frente de Liberación Nacional, quedando ausente de nuestro análisis el debate aparecido a propósito del contexto internacional más allá de la Revolución Cubana, donde tomarán importancia hechos como la invasión soviética a Hungría, el debate sobre el papel de la URSS en el "mundo socialista", la cuestión Chino-Soviética, Checoslovaquia, o las distintas consideraciones sobre el denominado tercer mundo. Consideramos que si bien estos elementos son importantes en la relación entre los partidos integrantes del FRAP, los debates que de estos hechos surgen son más bien coyunturales y no determinan posiciones ideológicas de gran influencia para el proyecto común de la izquierda, como sí lo hacen los debates aparecidos sobre el proyecto democristiano y los suscitados por Cuba. 


\section{Bibliografía}

\section{Publicaciones periódicas}

Boletines del comité ejecutivo del Partido Socialista Popular

Boletines del comité central del Partido Socialista

Revista Arauco

Revista Principios

\section{Fuentes primarias}

- Chelén, Alejandro. La revolución cubana y sus proyecciones en América Latina, Santiago, Ediciones Prensa Latinoamericana, 1960.

- Corvalán, Luis Camino de Victoria, Santiago, Impresora Horizonte, 1972.

- Democracia Cristiana, El ABC de la Democracia Cristiana. Cuadernos de divulgación doctrinaria, $\mathrm{N}^{\circ} 1$, Santiago, Editorial del Pacífico, Abril 1962.

- $\quad$ Dice la democracia cristiana a los Partidos Socialista y Comunista, Santiago, Editorial del Pacifico, 1963

- _ Un Programa y un Gobierno, Santiago, Editorial del Pacífico, Febrero de 1967.

- Frente de Acción Popular, Un camino nuevo para Chile: el programa del Gobierno Popular, Santiago, Impresora Horizonte, s/f.

- _ _ Programa del Gobierno Popular, Santiago, Imprenta Horizonte, 1964.

- Intervención del Senador Rodríguez. Diario de sesiones del Senado. Sesión 25, en 3 de enero de 1956.

- Intervención del Senador Allende. Diario de sesiones del Senado. Sesión 17, en 8 de julio de 1958

- Informe del Secretario General del Partido Socialista al XXI Congreso General Ordinario. 1965.

- Juventudes Demócrata Cristiana, Publicación de la comisión política $N^{\circ} 1, \quad L a$ Democracia Cristiana y la revolución en Libertad, s/e, Abril 1965.

- OCEPLAN, Las primeras 100 medidas del Gobierno Popular, Santiago, Impresora Horizonte, 1964.

- — L L L L L _ Política Agropecuaria del Gobierno Popular, Santiago, Impresora Horizonte, 1964.

- Partido Comunista de Chile, Programa del Partido Comunista de Chile, Santiago, Impresora Horizonte, 1962.

- $\longrightarrow$ Nuestros caminos conducen al socialismo. Respuesta del Partido Comunista de Chile al Partido Socialista, Santiago, Impresora Horizonte, 1966.

- _ Programa del Partido Comunista de Chile, Santiago, Impresora Horizonte, 1969.

- Partido Socialista de Chile, El socialismo y la unidad. Cartas del Partido Socialista al Partido Comunista, Santiago, Prensa Latinoamericana, 1966. 
- _ـ 1964: año de prueba para la revolución chilena. Informe del Secretario General al XX Congreso del Partido Socialista, Santiago, Ediciones Prensa Latinoamericana, 1964.

- Waiss, Oscar, "Cuba: Una experiencia heroica. Las enseñanzas de una revolución", Cuadernos de información política, N3, Santiago, Ediciones Socialismo, 1960.

- Waiss, Oscar, El espejismo del 64, Santiago, Imprenta Victoria, 1962.

- Waiss, Oscar, Basura teórica y traición política, Santiago, Ediciones El Gallo Rojo, 1964.

\section{Fuentes secundarias}

- Álvarez, Rolando, Arriba los pobres del mundo. Cultura e identidad del Partido Comunista de Chile entre democracia y dictadura, 1965-1990, Santiago, Lom, 2011.

- Casals, Marcelo, El alba de una revolución. La izquierda y la construcción estratégica de la "vía chilena al socialismo". 1956-1970, Santiago, Lom, 2010

- Corvalán Marquez, Luis, Del Anticapitalismo Al Neoliberalismo en Chile: Izquierda, Centro y Derecha en la Lucha Entre Los Proyectos Globales. 1950-2000, Santiago, Editorial Sudamericana, 2002.

- Collini, Stefan, et al, "What is intellectual history?", History Today, Vol. 35, No10, octubre 1985.

- Faúndez, Julio, Izquierdas y democracia en Chile 1932-1973, Santiago, Ediciones BAT, 1992.

- Fermandois, Joaquín, La revolución inconclusa. La izquierda chilena y el gobierno de la Unidad Popular, Santiago, Centro de Estudios Públicos, 2013.

- Freeden, Michael, Ideologies and political theory, Oxford, Oxford University Press, 1996.

- Furci, Carmelo, The Chilean Communist Party and the Road to Socialism, Londres, Zed Press, 1984.

- Jobet, Julio César, El Partido socialista de Chile, Tomo II, Santiago, Ediciones Prensa Latinoamericana, 1971.

- Knight, Alan, "Democratic and Revolutionary Traditions in Latin America", Bulletin of Latin American Research, 20: 2, abril 2001.

- Ortega, Luis, "La radicalización de los socialistas de Chile en la década de 1960", Revista Universum, 23:2, 2008, pp. 162-174.

- Palieraki, Eugenia, ¡La revolución ya viene! El MIR chileno en los años sesenta, Santiago, Lom, 2014.

- Pinto, Julio, "Hacer la revolución en Chile", en J. Pinto (ed.), Cuando hicimos historia. La experiencia de la Unidad Popular, Santiago, Lom, 2005.

- Venegas, Hernán, "El Partido Comunista de Chile: antecedentes ideológicos de su estrategia hacia la Unidad Popular (1961-1970)", Revista de Historia Social y de las Mentalidades, $\mathrm{N}^{\circ}$, vol. 2, 2003. 